printing the Pad in a distinctive color to enhance its use as a clinician reminder and adding visual icons for use with low-literacy patients in place of written advice. ${ }^{2}$ What started as a prescription pad for health behavior change was transformed through the cumulative wisdom of 7 practices into a new, multipurpose tool.

\section{CONCLUSIONS}

Although we intended to tailor the tools to practices' needs, the methods used in this study facilitated changes in the tools' intended use and design beyond our expectations. For such innovations to occur, the research team must assume roles as both learners and conduits of cumulative participant wisdom, rather than as experts.

To read or post commentaries in response to this article, see it online at http://www.annfammed.org/cgi/content/full/3/Suppl_2/S54.

Key words: Health promotion; practice-based research network; health promotion/disease prevention; Internet; health behavior; patient education
Submitted January 25, 2005; submitted, revised, March 15, 2005; accepted March 21, 2005.

Funding support: This project was supported by Prescription for Health (grant No. 049058, Dr Flocke), a national program of The Robert Wood Johnson Foundation with support from the Agency for Healthcare Research and Quality. Dr Flocke was also supported in part by a career development award from the National Cancer Institute (CA 86046).

Acknowledgments: We wish to acknowledge the clinicians, staffs, and patients from the 7 family practices that participated in this project: Neighborhood Family Practice; the practice of Drs Weinberger and Vizy, and Ms DuBay, PA; the practice of Dr Kellner; the practice of Dr Kirsch; Southwest Family Physicians; the Metrohealth Thomas F. McCafferty Health Center; and University Primary Care (Bedford location).

\section{References}

1. Swinburn BA, Walter LG, Arroll B, Tilyard MW, Russell DG. The green prescription study: a randomized controlled trial of written exercise advice provided by general practitioners. Am J Public Health. 1998;88:288-291.

2. Houts PS, Witmer JT, Egeth HE, Loscalzo MJ, Zabora JR. Using pictographs to enhance recall of spoken medical instructions II. Patient Educ Couns. 2001;43:231-242.

\title{
Minnesota Clinicians Motivating Health Improvement (MINIT) Study: Motivating Healthy Habits
}

\author{
Kevin A. Peterson, $M D, M P H_{i}{ }^{1}$ Tai Mendenball, $P b D, L_{M F T}{ }^{1}$ Sharon Allen, $M D, P b D_{i}{ }^{1}$ Helen Roembild, MEd, CCRP ${ }_{i}{ }^{2}$ \\ Pamela Werb, MEd, CCRP, CCRC ${ }^{2}$ Mark Janowiec, $A A_{i}{ }^{1}$ Richard Botelho, BM, BD, MRCGP \\ For the Minnesota Academy of Family Physicians Research Network (MAFPRN) \\ 'Department of Family Medicine and Community Health, University of Minnesota Medical School; Minneapolis, Minn \\ ${ }^{2}$ WWPI Research and Consulting, Minneapolis, Minn \\ ${ }^{3}$ University of Rochester School of Medicine, Rochester, NY
}

Ann Fam Med 2005;3(Suppl 2):S56-S58. DOI: 10.1370/afm.363.

Conflicts of interest: Dr. Botelho is owner of www.MotivateHealtbyHabits.com, the MHH online learning program, and MHH publication, LLC.

Kevin A. Peterson, MD, MPH, Department of Family Medicine and Community Health, University of Minnesota Medical School, 925 Delaware St SE, Suite 220, Minneapolis, MN 55414, peter223@umn.edu

\section{PURPOSE}

$\mathrm{T}$ The MINIT (Minnesota Clinicians Motivating Health Improvement) Study was designed to target 4 risk behaviors that are strongly linked to a variety of negative health outcomes in the United States: (1) cigarette smoking, (2) sedentary lifestyle, (3) poor diet, and (4) risky drinking.

The specific purpose of this investigation was to field-test an interactive educational program that implemented a motivational approach to behavior change in order to enhance the use and success of established behavior-specific modification programs.

\section{METHODS}

We recruited for the study 114 patients from 10 participating community-based primary care clinics within the Minnesota Academy of Family Physicians Research Network (MAFPRN). Subjects were initially identified by the physician or site coordinator as having 1 of the 4 targeted risk behaviors, and were not actively participating in behavior change or a behavioral intervention program. After introducing the study to patients and obtaining appropriate consent, we asked participants a set of questions to assess their readiness to change. They were also assessed on a scale of 10 motivational 
process measures, and finally they selected 1 of the 4 risk behaviors to serve as their focus for the remainder of the study. Patients were asked to choose 1 of the following motivational intervention options to assist in self-assessment of their motivation and behavior: (1) a self-help guidebook ${ }^{1}{ }^{1}(2)$ the guidebook plus telephone counseling, or (3) an Internet-based course with telephone counseling. The motivational intervention was not intended to substitute for a weight loss program, smoking cessation program, exercise program, or alcohol cessation program. If participants sought to address a specific unhealthy behavior as a result of the motivational intervention, their physician or study coordinator assisted them with existing community resources.

We recruited 4 local and national organizations as existing resources for behavior-specific support. The Minnesota Partnership for Action Against Tobacco provided self-help materials as well as telephone counseling support in smoking cessation. Hazelden Foundation was identified as a resource for addressing risky drinking. The Small Steps, Big Rewards program from the National Institute of Diabetes and Digestive and Kidney Diseases was a resource for addressing poor diet, and Be Active Minnesota provided self-help and Internet resources to address sedentary lifestyle. Study clinics and the central study center were then able to refer participants who became more motivated during the study to appropriate resources located within their own community.

Participants generally completed the self-help guidebook $^{1}$ in 1 to 3 hours. The guidebook plus telephone counseling intervention entailed working through the guidebook, and 2 telephone calls, each lasting 20 minutes (with 2 to 3 brief additional calls if desired). The Internet-based course entailed 2 sessions, each lasting approximately 40 minutes. Research staff contacted participants by telephone at baseline and again 30 days and 180 days thereafter for followup. During these calls, staff specifically focused on 10 motivational process measures, subjects' readiness to change, and the use of existing change programs

\section{LESSONS LEARNED}

The research consent process itself was an important element in successfully initiating patients' readiness to change and promoting risk-specific behavior change. This brief patient-physician encounter appeared to influence the recruitment to and the effectiveness of all subsequent interventions. The impact of patients' personal physician asking if they are interested in thinking about behavior change, not actually beginning any riskspecific intervention, appeared to start the process of changing their stage of readiness.

The consent process augmented the impact of the subsequent motivational intervention and was not captured by our baseline tool. Because baseline measures were assessed after the consent process, subsequent change in readiness reflects the initial patient-physician study enrollment discussion, the time spent completing the process of informed consent, and finally, the impact of the motivational intervention as designed in the study.

Regular and direct contact with a person (ie, telephone calls instead of e-mail) appears to be a key element in successful behavioral change. Human interaction was the preferred method of promoting behavioral change. Although participants were very responsive to our 30-day and 180-day follow-up telephone contacts, they did not initiate any telephone calls into our central site for additional counseling support, yet they remained engaged in our study design.

Participants who had selected self-help as their intervention regularly discussed motivation and behavior change during their follow-up telephone calls, which were intended to be scripted. "Self-help" therefore usually spontaneously converted to telephone support after patients received the 30-day follow-up telephone call.

For 3 of the risk behaviors studied-smoking, sedentary lifestyle, and poor diet - the variety of intervention options was successful in providing most participants with essential commitment to the study and progress toward improving the behavior. Patients in the risky drinking group, however, chose to leave the study before the baseline survey was conducted.

\section{CONCLUSIONS}

Initial conversations with patients can strongly influence their health behavior change process and are not as difficult as commonly perceived. The consent process is an important interaction in initiating behavioral change and has the potential to confound evaluation of behavioral interventions. In particular, physicianobtained consents have a positive effect on readiness to change and likely enhance the effect of subsequent motivational interventions.

It is important to provide real human contact and follow-up to subjects to instill a sense of accountability in behavior change. Our findings suggest that offering patients a variety of intervention options can promote both initial readiness to change and progress toward smoking cessation, increased physical activity, and healthier diet.

To read or post commentaries in response to this article, see it online at http://www.annfammed.org/cgi/content/full/3/Suppl_2/S56.

Key words: Primary care; practice-based research network; health behavior; behavioral/psychosocial; health promotion/disease prevention; smoking; alcohol drinking; physical activity 
Submitted December 23, 2004; submitted, revised, March 25, 2005; accepted March 31, 2005.

Funding support: This project was supported by Prescription for Health, a national program of The Robert Wood Johnson Foundation with support from the Agency for Healthcare Research and Quality.

Acknowledgments: We would like to thank several groups for their important role in the successful completion of this investigation. For its generous funding and energizing vision, we thank the Robert Wood Johnson Foundation. For its recruiting of subjects and collaboration with community partners, we thank the following MAFPRN clinics: CentraCare Clinic/Long Prairie, Creekside Family Physicians, Fairview Clinic/Eden Prairie, Park Nicollet Clinic/Minnetonka, Parkview Medical Clinic, Payne
Avenue Clinic, Parkview Medical Clinic, Phalen Village Clinic, Soteria Family Health Center, Starbuck Clinic, and Willmar Family Practice Clinic. For their active involvement in informing our early conceptualizations of this work, and ongoing availability to patients seeking assistance with important behavioral change, we thank the following community partners and advisors: Hazelden Foundation, Minnesota Partnership for Action Against Tobacco, National Institute of Diabetes and Digestive and Kidney Diseases, Be Active Minnesota, Blue Cross Blue Shield of Minnesota, and the Park Nicollet Institute.

\section{References}

1. Botelho R. My Health Habits Journal. Rochester, NY: MHH Publications; 2003.

\title{
Reducing Tobacco Use and Risky Drinking in Underserved Populations: The Need for Better Implementation Models
}

\author{
Bonnie McRee, $\mathrm{MPH}_{i}{ }^{1}$ Jennifer Granger, $\mathrm{MPH}_{i}{ }^{2}$ Thomas Babor, $\mathrm{PbD}, \mathrm{MPH}{ }_{i}{ }^{1}$ Ingrid Feder, $\mathrm{MD}_{i}{ }^{3}$ Audie Horn, $\mathrm{Jr}_{r} \mathrm{PA}-\mathrm{C}, \mathrm{CDE}_{i}{ }^{4}$ \\ Judith Steinberg, $M D_{i}^{5}$ Keith vom Eigen, $M D, P b D, M P H^{6}$ \\ 'University of Connecticut Health Center, Department of Community Medicine and Health Care, Farmington, Conn \\ ${ }^{2}$ Connecticut Primary Care Association, Hartford, Conn \\ ${ }^{3}$ Community Health Center, Inc, New London and Groton, Conn \\ ${ }^{4}$ Katahdin Valley Health Center, Island Falls and Patten, Me \\ ${ }^{5}$ Harbor Health Services, Boston, Mass \\ ${ }^{6}$ Burgdorf/Fleet Health Center, St Francis Hospital and Medical Center, Hartford, Conn
}

Ann Fam Med 2005;3(Suppl 2):S58-S60. DOI: 10.1370/afm.362.

Conflicts of interest: none reported

CORRESPONDING AUTHOR

Jennifer Granger, MPH, Director of Clinical Affairs, Connecticut Primary Care Association, 90 Brainard Rd, Suite 101, Hartford, CT 06114, jgranger@ ctpca.org

\section{PURPOSE}

T The prevalence of many health behavior risk factors (eg, smoking, risky drinking, physical inactivity) are highest among uninsured and Medicaid-eligible populations. ${ }^{1}$ Screening and brief behavioral counseling in high-volume Federally Qualified Health Centers (FQHCs) are key elements of a cost-effective public health approach to the early identification and management of high-risk patients. This project examined 3 different ways to implement a combined screening and brief intervention $(\mathrm{SBI})$ program for smokers and at-risk drinkers in FQHCs.

\section{METHODS}

Practices in 6 New England FQHCs were randomized to 1 of 2 SBI implementation models: the clinician model, in which a physician or physician's assistant conducted the brief counseling services; or the specialist model, in which a staff medical assistant or nurse conducted the brief counseling services. In all, 24 clinicians and 13 specialists participated. A seventh practice was selected to test a health educator model, in which an external assistant who was not a staff member conducted the SBI services. Key staff from the general medicine departments at each site participated in a 3-hour continuing medical education-accredited training session before beginning a 4-month implementation phase. The implementation phase was followed by a 4-month sustainability phase during which the sites had less frequent contact with the research team, but continued to conduct SBI and were monitored for progress. SBI was conducted using standardized procedures for risk factor screening combined with brief counseling for smoking cessation or reducing risky drinking. ${ }^{2,3}$

The relative penetration of each model was assessed, along with changes in clinicians' attitudes, knowledge, 